\title{
Mef2A, a homologue of animal Mef2 transcription factors, regulates cell differentiation in Dictyostelium discoideum
}

\author{
María Galardi-Castilla ${ }^{1}$, Irene Fernandez-Aguado ${ }^{1}$, Teresa Suarez ${ }^{2}$ and Leandro Sastre ${ }^{1 *}$
}

\begin{abstract}
Background: Transcription factors from the MADS-box family play a relevant role in cell differentiation and development and include the animal SRF (serum response factor) and MEF2 (myocyte enhancer factor 2) proteins. The social amoeba Dictyostelium discoideum contains four genes coding for MADS-box transcription factors, two of these genes code for proteins that are more similar to SRF, and the other two code for proteins that are more similar to MEF2 animal factors.

Results: The biological function of one of the two genes that codes for MEF2-related proteins, a gene known as mef2A, is described in this article. This gene is expressed under the transcriptional control of two alternative promoters in growing cells, and its expression is induced during development in prespore cells. Mutant strains where the mef2A gene has been partially deleted were generated to study its biological function. The mutant strains showed reduced growth when feeding on bacteria and were able to develop and form fruiting bodies, but spore production was significantly reduced. A study of developmental markers showed that prespore cells differentiation was impaired in the mutant strains. When mutant and wild-type cells were set to develop in chimeras, mutant spores were underrepresented in the fruiting bodies. The mutant cells were also unable to form spores in vitro. In addition, mutant cells also showed a poor contribution to the formation of the tip-organizer and the upper region of slugs and culminant structures. In agreement with these observations, a comparison of the genes transcribed by mutant and wild-type strains during development indicated that prestalk gene expression was enhanced, while prespore gene expression decreased in the mef2 $A^{-}$strain.
\end{abstract}

Conclusions: Our data shows that mef2A plays a role in cell differentiation in D. discoideum and modulates the expression of prespore and prestalk genes.

Keywords: Myocyte enhancer factor 2, Dictyostelium, Cell differentiation, Development, Cell-type patterning, Transcription factor

\section{Background}

Mef-2-related transcription factors belong to a family of proteins that are present in all eukaryotic organisms [1,2]. These proteins share a very conserved DNA-binding and protein-dimerization domain, the MADS-box, named after the transcription factors MCM1 (from yeast), Agamous, Deficiens (from plants) and SRF (from animals) $[3,4]$. Two subfamilies of MADS-box transcription factors have been defined according to the MADS-box sequence:

\footnotetext{
* Correspondence: Isastre@iib.uam.es

${ }^{1}$ Instituto de Investigaciones Biomédicas de Madrid (Biomedical Research Institute of Madrid), CSIC/UAM, C/Arturo Duperier 4, 28029, Madrid, Spain Full list of author information is available at the end of the article
}

type I and type II [5]. Plants have a large number of types I and II MADS-box proteins while other organisms, such as fungi and animals, usually have one or more proteins of each subfamily [6]. Animals, for example, have only one type I protein (serum response factor [SRF]) and four type II proteins (myocyte enhancer factor 2 A-D [Mef2 A-D]). The two types of factors recognize different $\mathrm{A} / \mathrm{T}$ rich binding sites. SRF and related factors recognize the consensus sequence $\mathrm{CC}(\mathrm{A} / \mathrm{T})_{6} \mathrm{GG}[7,8]$, while Mef-2-related factors recognize the $\mathrm{CTA}(\mathrm{A} / \mathrm{T})_{4} \mathrm{TAG}$ consensus sequence [9].

MADS-box transcription factors accomplish various biological functions. In plants, they are critically involved in floral formation and development [5]. In yeasts,

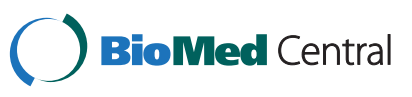


MCM1 participates in the regulation of pheromone expression, metabolism [10] and DNA replication [11]. In animals, these transcription factors are mainly involved in the regulation of cell-differentiation processes. SRF deletion is lethal in mice because cells are impaired in cell adhesion and migration [12], and the embryo cannot complete gastrulation [13]. Tissue-specific deletion has shown that SRF is also required for terminal differentiation of skeletal, cardiac and smooth muscle cells and for neural cell migration [14]. Additional studies have demonstrated that SRF regulates the expression of a large number of genes coding for actin-cytoskeleton-related proteins $[15,16]$.

Mef-2 proteins are involved in regulating the expression of muscle-specific genes, both in Drosophila [17] and in mammals [18], in collaboration with MyoD-related transcription factors [19]. In mammals, there are four genes coding for very similar Mef-2 factors that appear to functionally complement each other, at least partially (Mef2A-D) [20]. However, Mef2C-null mice die early in their development due to cardiovascular abnormalities [21], and Mef2A-null mice die perinatally from heart defects [22]. In addition, numerous studies have shown that Mef-2 factors are also involved in the differentiation of several other cell types, such as neural crest cells, endothelial cells, chondrocytes, neurons and lymphocytes [23,24].

Our group has approached the functional study of MADS-box transcription factors in the social amoeba Dictyostelium discoideum. These unicellular organisms live in forest soils, feeding on bacteria and other microorganisms and are able to develop as multicellular organisms under starvation conditions. In such conditions, up to $10^{5}$ individual amoebas aggregate to form a fruiting body composed of a basal disk, stalk and sorus where up to $80 \%$ of the original amoeba differentiate into resistant forms called spores [25-27]. The initial step is the aggregation of the cells towards cAMP-secreting centers to form a mound. Cells within the aggregates initiate a differentiation process to form two main cell types: prestalk and prespore. Prestalk cells migrate to the top of the mound, emerging as a tip. A culmination process is later initiated by the migration of prestalk cells from the tip towards the substrate through the mass of prespore cells, piling up and terminally differentiating to form the stalk. The mass of prespore cells remains attached to the top of the forming stalk, rising from the substrate until culmination is completed. Migratory structures, called slugs, can be formed before culmination under adverse environmental conditions. In this case, the slugs migrate towards warmer and lighter places for culmination to facilitate the dissemination of the spores. By the end of culmination, prespore cells differentiate inside the sorus to form mature spores.

Analysis of the $D$. discoideum genome has shown that it contains four genes coding for MADS-box transcription factors, namely $\operatorname{srfA}, \mathrm{B}, \mathrm{C}$ and D. Previous studies in our laboratory have shown that $s r f A$ is required for the proper development of the fruiting body, including the slug migration and culmination steps, and is essential for spore terminal differentiation $[28,29]$. The $\operatorname{srf} B$ gene is expressed earlier than srfA during development, and the encoded protein is involved in the initiation of the developmental process, cell migration and the initiation of culmination [30]. The functional study of the $\operatorname{srfC}$ gene is described in this article. We present evidence demonstrating that $\operatorname{srfC}$ is more similar to animal Mef-2 genes and propose naming it mef $2 A$. By analyzing the phenotype of mutant strains and gene expression levels during development, we clearly show that this protein is involved in D. discoideum development and, in particular, in the differentiation of prespore cells and one group of prestalk cells.

\section{Results}

\section{Characterization of the mef2A (srfC) gene}

The analysis of the $D$. discoideum genome identified four genes coding for proteins with regions similar to the MADS-box domain. These genes were named $\operatorname{srfA}, B, C$ and $D$. The putative MADS-box region of the proteins encoded by these genes was analyzed in more detail and compared to that of vertebrates (H. sapiens, G. gallus, X. laevis), invertebrates (D. melanogaster, A. franciscana), amoeba (E. histolytica) and fungi (S. cerevisiae) type I (SRF, MCM1, ARG1) and type II (Mef2) proteins. Amino acid sequences were aligned using the ClustalW and ClustalX programs (Additional file 1: Figure S1). The multiple alignments were used to calculate the phylogenetic tree shown in Figure 1 . The results indicate that the $D$. discoideum genes $\operatorname{srfA}$ and $\operatorname{srfB}$ code for proteins that are more similar to type I genes, such as the animal SRF gene, than to type II genes, such as Mef2. D. discoideum SrfA and SrfB appear to form a monophyletic group that more closely resembles to animal proteins than to fungi proteins. In contrast, the proteins encoded by $D$. discoideum srfC and srfD are more similar to animal MEF2 than to SRF proteins. In this case, the protein encoded by $s r f C$ is more closely related to that of the amoeba E. histolytica and is also more similar to animal Mef2 proteins than to SrfD. In fact, SrfD appears to have diverged significantly from the other type II proteins analyzed. The results of this analysis centered our attention on $\operatorname{srfC}$, which we propose to rename as $m e f 2 A$, a name that we will use throughout the rest of the article.

The expression of mef $2 A$ during vegetative growth and development was analyzed by RT-PCR, and the results are shown in Figure 2A. Expression was detected in growing cells (time 0 in Figure 2A), but a large induction was observed at 4 hours of development, an induction that was maintained at later developmental stages. The promoter region of the gene was characterized to further determine the temporal and spatial patterns of 


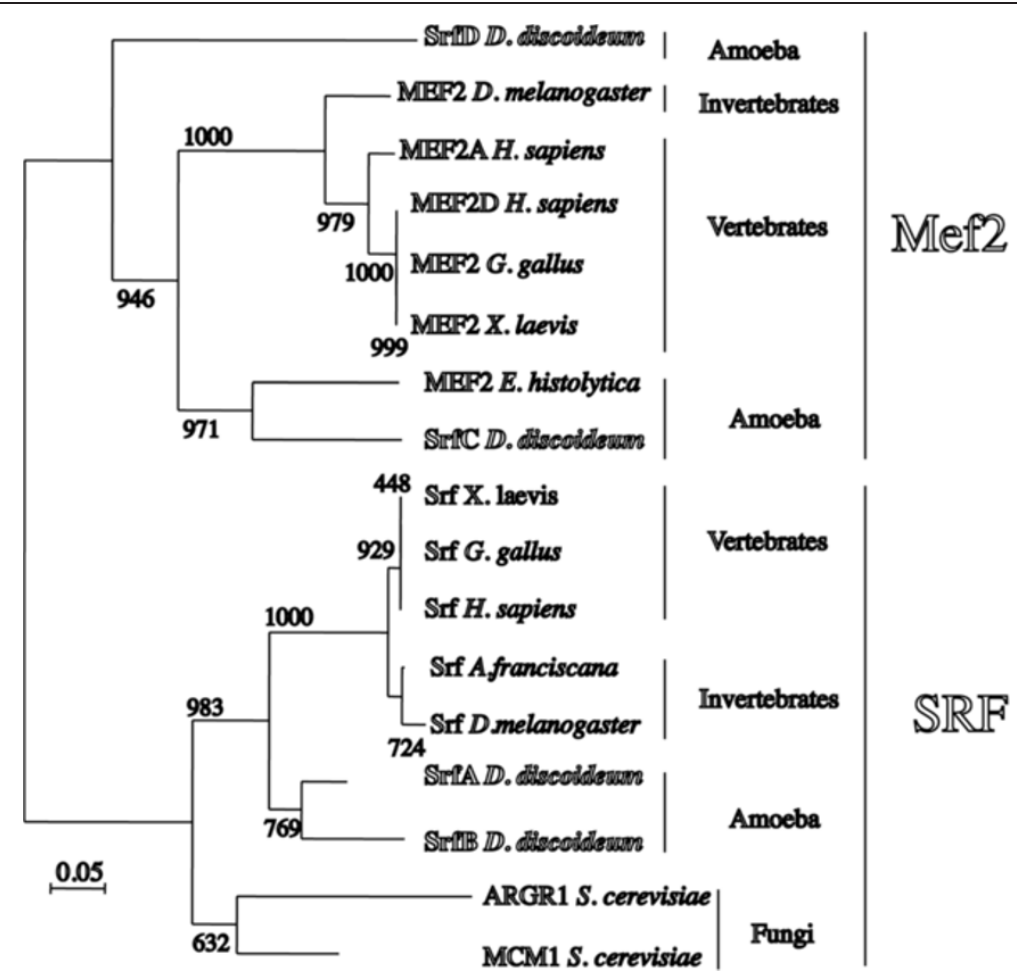

Figure 1 Phylogenetic tree of the $D$. discoideum MADS-box-containing proteins. The amino acid sequences of the MADS-box region from MEF2 and SRF proteins from vertebrates (H. sapiens, X. laevis, G. gallus), invertebrate (D. melanogaster, A. franciscana) animals, fungi (S. cerevisiae) and amoeba (E. histolytica) were compared to those of the four D. discoideum MADS-box containing proteins (SrfA, B, C and D) using the ClustalW program at the online Biology Work Bench facility from the San Diego Supercomputer Center (http://workbench.sdsc.edu). Phylogenetic trees were determined using the neighbor-joining method and the ClustalX program. A random generator seed of 111 was used, and 1000 bootstrap trials were calculated. The number of times that each branch was obtained is indicated at the base of each branch. The tree was drawn using the NJplot program. The evolutionary distance scale, calculated as a fraction of amino acid changes, is indicated at the left lower corner of the figure.

expression. Primer-extension experiments were performed using the RACE (rapid amplification of cDNA ends) technique. The data indicated the existence of one intron in the $5^{\prime}$ UTR and two regions of transcription initiation (Additional file 1: Figure S2) [GenBank:KC852901]. The gene structure diagram, which includes the $5^{\prime}$ untranslated region (UTR) and the transcription initiation sites, is shown in Figure 2B. The more upstream transcription initiation sites of each region are located at nucleotides -144 and -814 , respectively. The first intron is located in the $5^{\prime}$ UTR of one of the two transcribed mRNAs (nucleotides -536 to -371 , in relation to the A of the initiation codon). The data obtained from the experiments also enabled us to define the limits of the second intron, located between the first (A) and second nucleotide $(\mathrm{T})$ of the translation initiation codon.

The transcriptional activity of both promoters was analyzed by the use of reporter vectors where Promoter 1 (Pr1), Promoter 2 (Pr2) or the complete promoter region (cPr) were cloned, thereby driving lac $Z$ expression. Pools of transformed cells obtained for each promoter were analyzed for $\beta$-galactosidase activity. Promoter 1 drove lac $Z$ expression in scattered cells at the mound and finger stages of development, but its activity markedly increased in the prespore region of slug, Mexican-hat and culminant structures (Figure 2C). Promoter 2 was active in scattered cells of aggregates and fingers, but the activity decreased almost completely at later developmental stages, except for a few cells in the basal disk of culminant structures. The activity of the complete promoter showed the sum of Pr1 and Pr2 and was maximal in the prespore region of developing structures.

\section{Generation of mef2A-deficient strains}

The study of the biological function of $m e f 2 A$ was approached through the generation of mutant strains where the gene was partially deleted by homologous recombination. The deleted region included the first two exons, coding for the $5^{\prime}$ untranslated region of the gene, and the third exon, coding for the $\mathrm{N}$-terminal region of the protein, including the MADS-box domain (Figure 2B). Several mutant clones were isolated on two different backgrounds, the AX2 and AX4 D. discoideum axenic strains. Figure 3A shows the RT-PCR analyses demonstrating $m e f 2 A$ gene deletion in one AX4-derived clone (37) and two AX2-derived clones $(2,3)$. Later results show no 

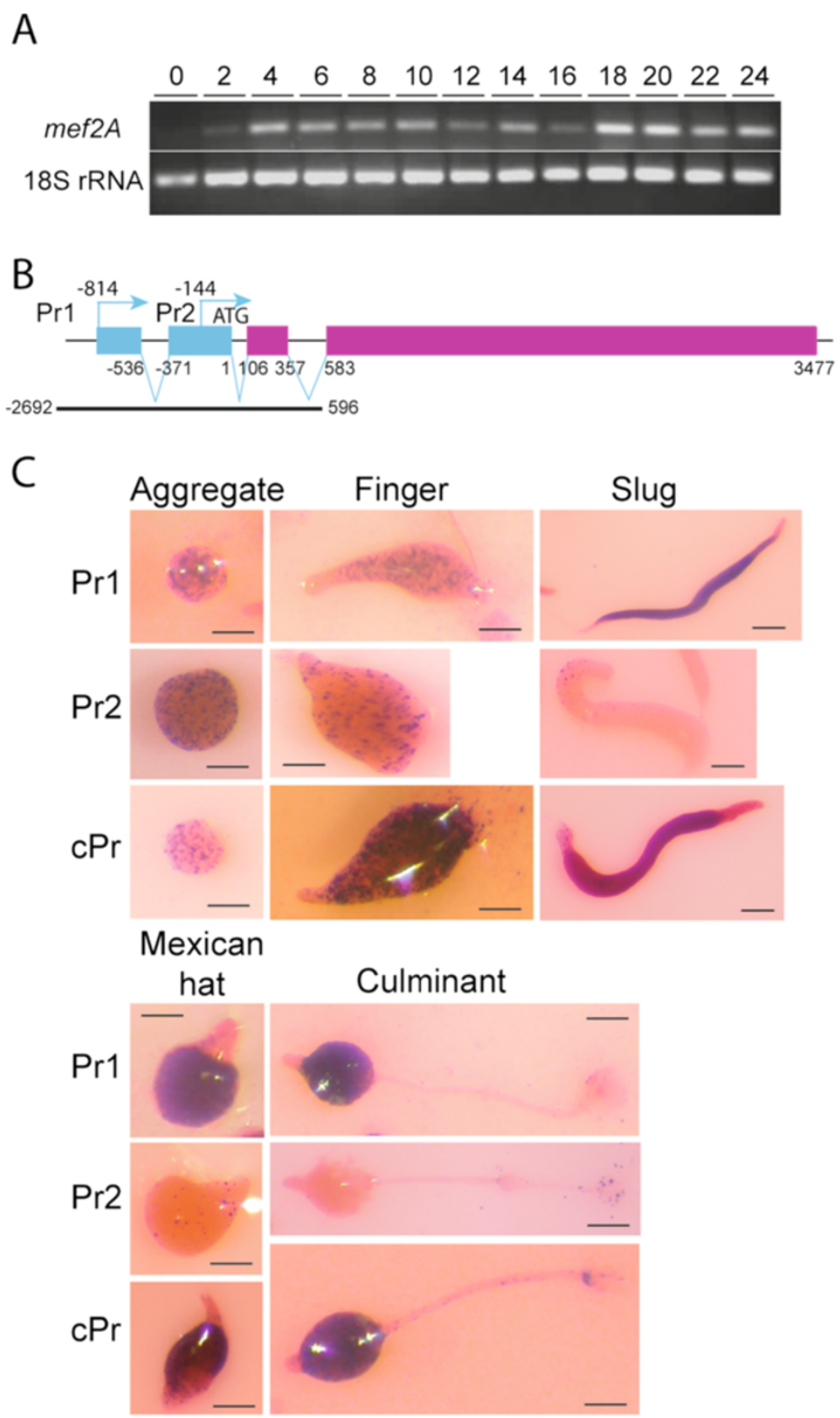

Figure 2 Structure and expression of the mef2A gene. Panel A. RNAs were isolated from AX4 cells during growth (0) or after development (2-24 hours). Expression of mef2A or the large mitochondrial rRNA (internal control), were determined by PCR. Panel B. RNA purified from AX4 cells developed for 8 hours was converted into CDNA, and the $5^{\prime}$ end extended using an oligonucleotide complementary to nucleotides 145 to 164 of the gene. Two different amplification products were obtained and their nucleotide sequences aligned to the genomic DNA. A diagram of the deduced structure of the gene is shown. Exon sequences are indicated as boxes, blue boxes for untranslated regions and deep red boxes for translated regions. Arrows indicate transcription initiation sites. The sequence has been numbered from the A of the translation initiation codon. The location of intron/exon borders is indicated on the lower part of the diagram and that of transcription initiation sites in the upper part. The DNA fragment deleted in the mutant strains is indicated in the lower part of the diagram. Panel $\mathbf{C}$. The activity of the mef2A promoter regions was studied using lacZ reporter vectors driving the expression of a short-lived form of $\beta$-galactosidase. The region from the $3^{\prime}$ end of the closest upstream gene (-2201) to the end of exon 1 (-489) (Pr1) and from the end of exon 1 (-511) to exon 3 (164) (Pr2), or the complete promoter region (-2201 to 164) (CPr), were cloned. lacZ expression was analyzed by histochemistry, using the Xgal substrate (2 hours of incubation) in aggregates (10 hours of development), finger (16 hours), slug (24 hours of development under migration conditions), Mexican hat (18 hours) and culminant (22 hours) structures. Pictures were taken using a Leica stereomicroscope, after counter-staining with eosin. Scale bar: $0.2 \mathrm{~mm}$. 
A
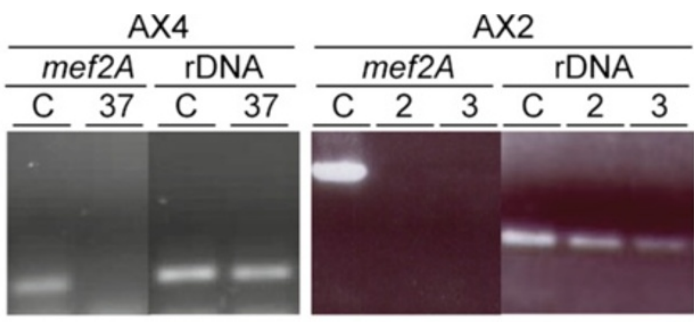

B

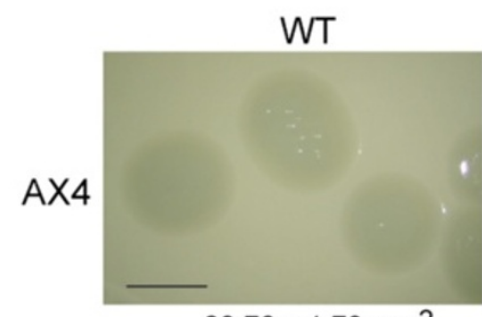

$29,76 \pm 1,70 \mathrm{~mm}^{2}$

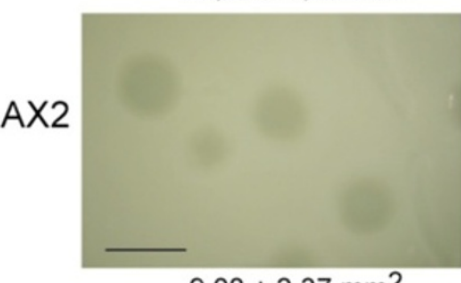

$9,08 \pm 2,37 \mathrm{~mm}^{2}$ $m e f 2 A^{-}$

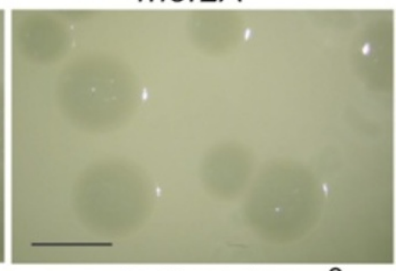

$15,00 \pm 1,14 \mathrm{~mm}^{2}$

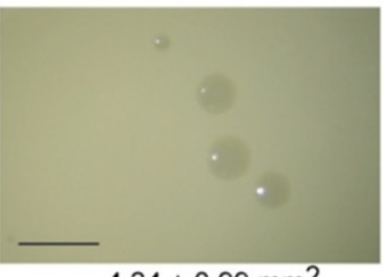

$4,24 \pm 0,99 \mathrm{~mm}^{2}$

C Mound

AX4
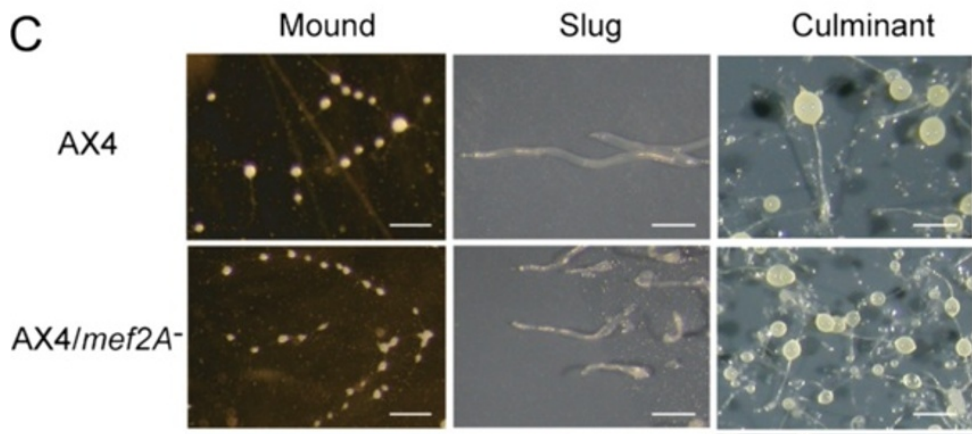

AX2
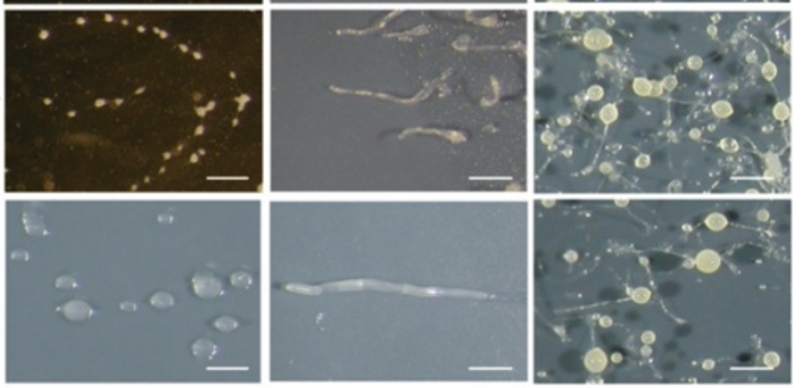

AX2/mef2A-
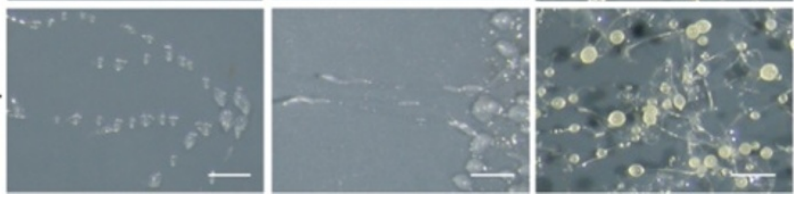

Figure 3 Generation and analyses of mef $2 A^{-}$mutant strains. Panel A. Mutant AX2 and AX4 strains were generated by partially deleting the mef2A gene through homologous recombination. DNA was isolated from several clones and analyzed by PCR using oligonucleotides specific for the mef2A- deleted region (mef2A) or for ribosomal DNA (rDNA) used as the internal control. The results obtained from non-mutated (AX4, AX2) and mutated (clones 37, 2 and 3 ) samples are shown. Panel B. Wild-type cells (AX4, AX2) and mef2A- mutant cells $\left(m e f 2 A^{-}\right)$, derived from AX4 or AX2 cells were clonally grown on $K$. aerogenes for 4 days. Biological replicates were performed on several different plates. Pictures of the colonies were taken, and their size determined in three independent experiments. The average area of the colonies and the standard deviations are indicated under each picture. Scale bar: $5 \mathrm{~mm}$. Panel C. Wild-type (AX4, AX2) and mutant cells (AX4/mef2A', AX2/mef2A) were collected and cultured under starvation conditions to study the multicellular development. The initial steps of aggregation, streaming and mound formation were assayed under submerged conditions (Mound column). For later stages of slug (Slug) and fruiting body (Culminant) formation, the cells were placed on nitrocellulose filters. Pictures were taken using a Leica stereomicroscope. Scale bar: $0.3 \mathrm{~mm}$. 
evidence of any transcription of the remaining coding DNA of this gene (Gene Expression profile of mef $2 A$ mutant cells Subsection). The mef $2 A^{-}$deleted strains grew more slowly than the wild type strains when feeding on bacteria (Figure 3B), although no difference in growth was observed in the axenic culture (data not shown).

The mutant strains completed development under starvation conditions at the same time as the wild-type strains, but several differences were observed during the process, as shown in Figure 3C. Both the mutant and wild-type strains formed streams during aggregation, but the streams of the mutant strain appeared more fragmented than those of the wild-type strains, forming more heterogeneous and smaller mounds. Subsequently, the mutant strains formed fewer slugs, which were smaller and migrated shorter distances than those formed by the wild-type strains. Finally, the mutant strains formed more culminant structures that were more heterogeneous in size than those of the wild-type strains. The number of spores formed by each strain was quantified, and the mutant strains produced about half the number of spores formed by the wild-type strains (Table 1). However, the viability of the mature spores was similar for the mutant and wild-type strains.

The developmental phenotype of the mutant was further characterized by studying the expression of celltype specific marker genes. AX4 and mef $2 A^{-}$mutant cells were transfected with reporter vectors that drive lac $Z$ expression under the control of the ecmA and ecmB prestalk gene promoters or the $p s p A$ prespore gene promoter. The lac $Z$ expression was analyzed at the finger, slug and mid-culminant stages of development (Figure 4). The ecmA gene promoter is active in the anterior, prestalk region of finger and slug structures (PstA region) and in the stalk, upper and lower cups and basal disk of wild-type structures. The activity was detected in the same regions in mef $2 A^{-}$mutants, but the anterior prestalk region was larger in the fingers. A quantification of the relative size of the PstA prestalk region indicated that it represented $23.45 \%$ (standard deviation: $5.27 \%$ ) of the finger length in AX4 structures and $31.16 \%$ (SD $6.62 \%)$ in the mef $2 A^{-}$mutants, difference that is statistically significant $(\mathrm{p}<0,001$ according to the student's test). In addition, ecmA promoter activity was more extended and diffuse in the mutant slugs. ecmB promoter

Table 1 Production of spores by wild type and $m e f 2 A^{-}$ mutant strains

\begin{tabular}{lll}
\hline Strain & Wild type & mef $2 \boldsymbol{A}^{-}$ \\
\hline $\mathrm{AX} 4$ & $100 \pm 13.5$ & $61.2 \pm 12.5$ \\
$\mathrm{AX2}$ & $100 \pm 13.9$ & $41.8 \pm 15.8$ \\
\hline
\end{tabular}

The value 100 indicates the average number of spores produced in AX2 or AX4 cells. The average and standard deviations of three biological replicates, made in triplicate, are shown. activity in the anterior prestalk region of mound and slug structures is more restricted than that of the ecmA promoter and is mainly located in the tip organizer region, as well as in a number of cells scattered around the posterior regions, i.e., the anterior-like cells [31]. In culminant structures, the $e \mathrm{cmB}$ promoter is active in the stalk. The mutant strains showed an extended region of ecmB promoter activity in the finger structures. In the slug structures, ecmB-expressing cells were more disperse in the mutant strains, and no well-defined tip organizer region was observed. The $p s p A$ prespore promoter presented a pattern of activity opposite to that of the ecmA promoter. In the fingers, the $p s p A$ promoter was active in the posterior, prespore region. The quantification of the $p s p A$ prespore region indicated that it is shorter in mef $2 A^{-}$mutants (61.32\%, SD 9.2\%) than in AX4 structures (70.92\%, SD $7.52 \%)(\mathrm{p}<0,001)$. In the culminant structures, $p s p A$ was active in the sorus. The mef $2 A$ mutants showed reduced $p s p A$ promoter activity, especially in the slugs where no well-defined prespore region was observed (Figure 4). In the culminant structures, the mutant sori were thinner than the wild-type sori.

The differences observed could be due to the participation of Mef2A in the process of prespore differentiation but could also be due to defective inter-cellular signaling in the mutant structures. We designed a developmental analysis of mixtures of the mutant and wild-type cells to discriminate between these two possibilities. In these experiments, we transfected wild-type and mutant cells with a reporter vector that would express $l a c Z$ upon differentiation of the cells to prestalk (ecmB::lacZ) or prespore (pspA::lacZ) cells. The transfected cells were mixed with non-transfected cells in a 1:4 proportion and allowed to develop. If the mef $2 A^{-}$mutant cells were defective in generating the intercellular signals required for cell differentiation, their mixture with wild-type cells would provide the defective signal and induce correct differentiation of the mutant cells. Alternatively, if the $m e f 2 A^{-}$mutant cells were defective in the process of cell differentiation, the presence of wild-type cells would not compensate for their differentiation defect. Therefore, wild-type and mutant cells expressing lac $Z$ from the prestalk-specific ecmB promoter or the prespore-specific $p s p A$ promoter were mixed with unlabeled cells and allowed to develop. The slugs and early culminant structures were analyzed for lac $Z$ expression, the results of which are shown in Figure 5. The expected distribution of ecmB-expressing cells can be observed in the AX4/AX4-lacZ samples. The ecmB-expressing cells are located in the tip-organizer region of the slugs, as well as scattered in their posterior region. In culminant structures, ecmB is expressed in the stalk (including the tip) and in the upper and lower- cup regions. The mixture of $m e f 2 A^{-}$mutant labeled and unlabeled cells showed a staining pattern similar to that shown in 


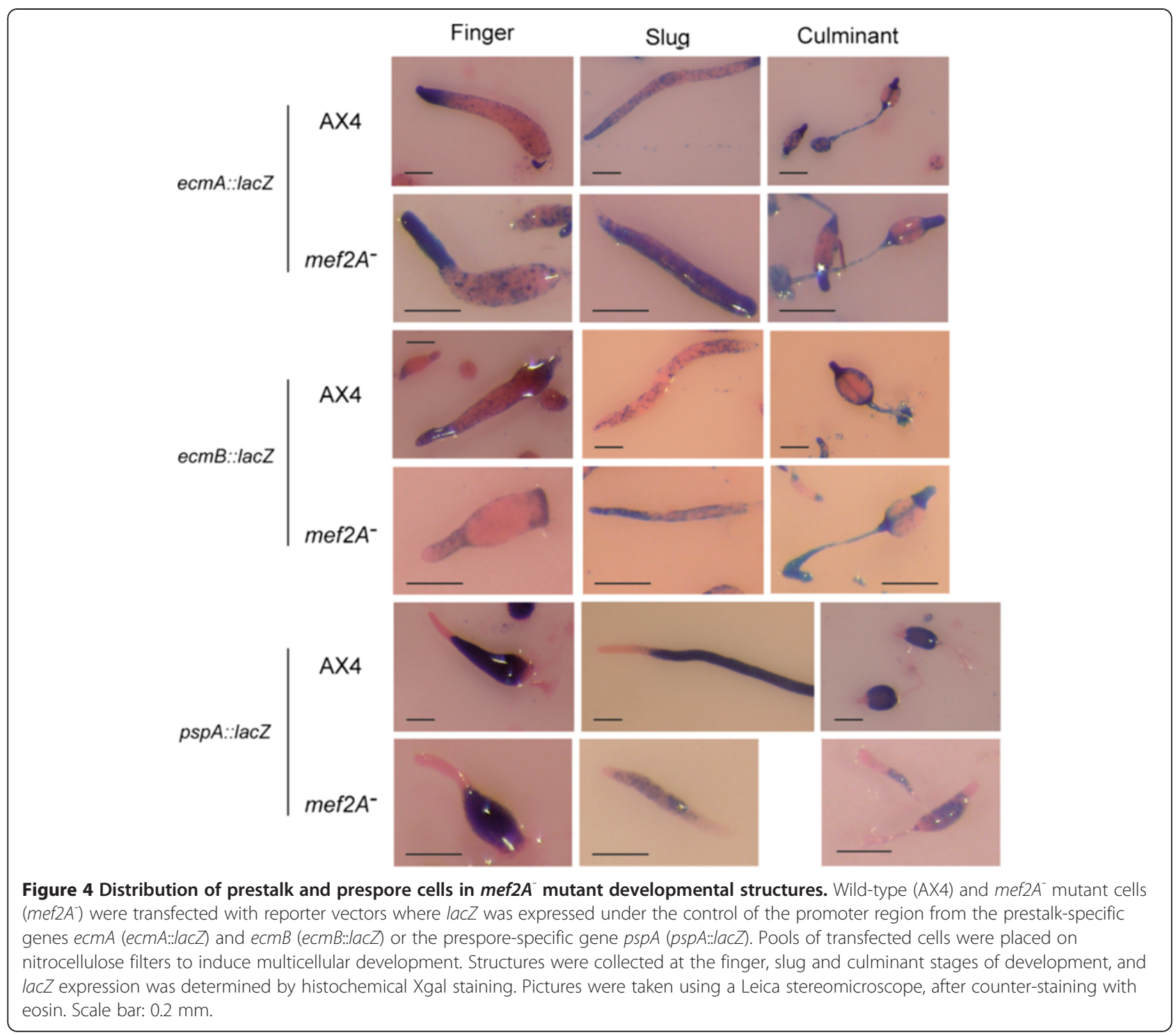

Figure 4 for ecmB::lacZ-expressing mutant cells. When the ecmB-expressing mef $2 A^{-}$cells were mixed with the wild-type cells, no lac $Z$ expression was detected in the tip organizer region in the slugs or in the tip of the culminant structures, indicating that the $m e f 2 A^{-}$cells were excluded from these regions. As expected, AX4-ecmB::lac $Z$ cells were found in these regions when mixed with mef $2 A^{-}$ cells, indicating that $m e f 2 A$ might be required for prestalk cell differentiation at the tip-organizer region.

The results obtained using $p s p A:: l a c Z$ as a cell marker are shown in the lower panel of Figure 5. Homogeneous mixtures of AX4/AX4 and mef $2 A^{-}$mutant/mef $2 A^{-}$mutant cells presented the same pattern of staining shown in Figure 4 . In the case of the mutant cells, a reduced population of lacZ-expressing cells was also observed in the slugs and, to a lesser extent, the culminant structures. The mixture of $p s p A$-labeled mef $2 A^{-}$mutant cells with wild-type unlabeled cells showed that very few mutant cells differentiated as prespore cells, and the cells that expressed $p s p A$ were found at the rear region of the slugs and the lower part of the sorus in the culminating structures. In contrast, intense lac $Z$ staining was observed when pspA-expressing AX4 cells were mixed with mef $2 A^{-}$ mutant cells.

Mixing experiments were also employed to study spore formation in chimeras. In this case, the cells were labeled (Cell-tracker, see MM) and mixed in a 1:1 proportion with unlabeled cells. Cells mixtures were set to develop and allowed to differentiate for 24 hours. Spores were collected, and the percentage of fluorescent spores was determined. Table 2 shows that homogeneous mixtures of wild-type (AX4 or AX2) or mef $2 A^{-}$mutant cells yielded the expected proportion of approximately 50\% fluorescent spores. However, the mixture of labeled wild-type cells 


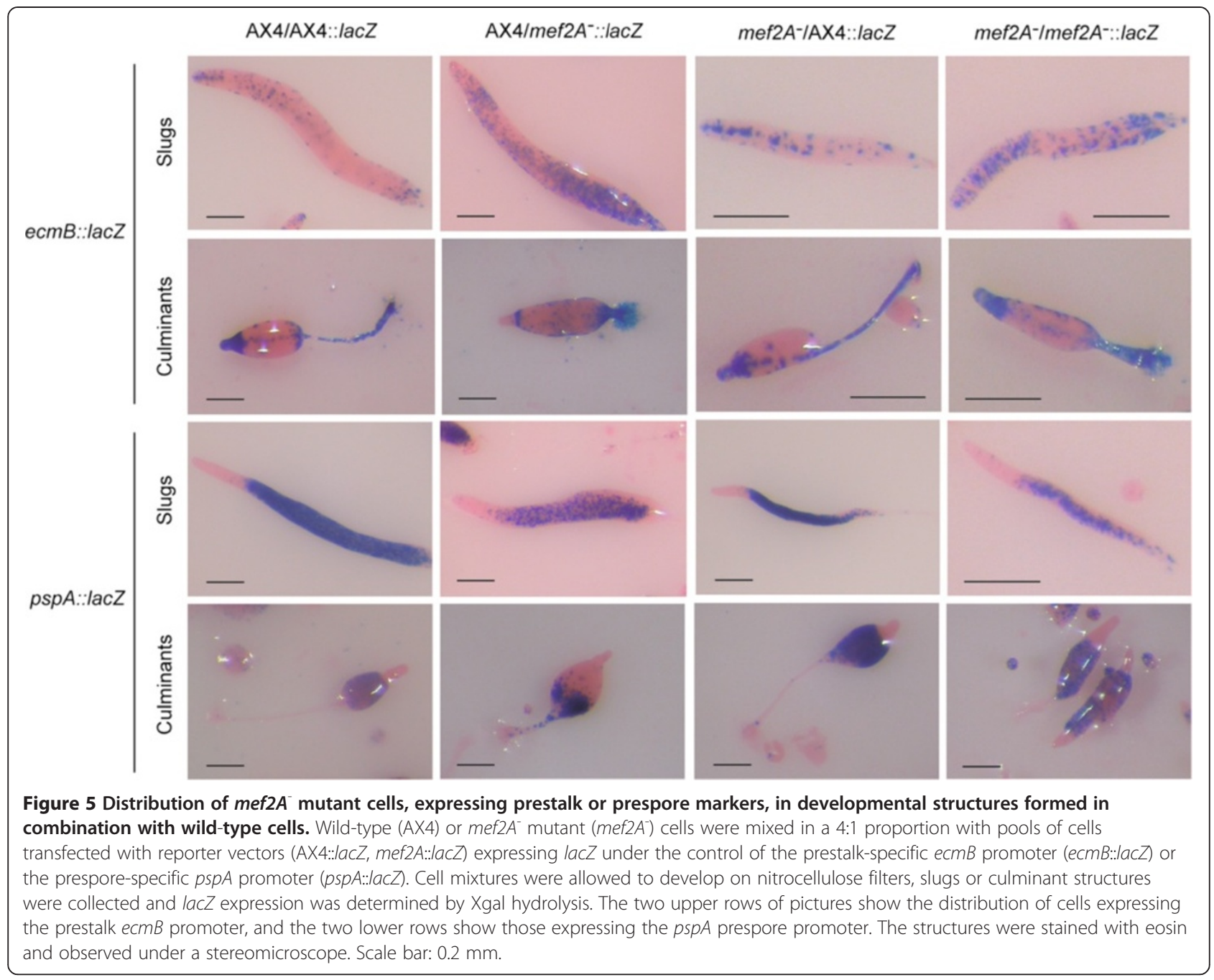

with unlabeled mef $2 A^{-}$mutant cells produced more than $90 \%$ fluorescent spores. In perfect agreement with this result, when labeled mef $2 A^{-}$cells were mixed with unlabeled wild-type cells, less than $10 \%$ of the spores showed fluorescence.

We also analyzed spore formation by in vitro differentiation. In these experiments, starved cells were induced to differentiate into spores by incubation with 8-Br-cAMP [32]. After 30 hours, the presence of differentiated spores

Table 2 Percentage of fluorescent spores in wild-type/ mef $2 A^{-}$mutant chimeric structures

\begin{tabular}{lll}
\hline & AX4 & AX2 \\
\hline $\mathrm{WT}^{\mathrm{FL}} / \mathrm{WT}$ & $42.4 \pm 6.5$ & $54.9 \pm 6.8$ \\
$\mathrm{WT}^{\mathrm{FL}} / \mathrm{mef} 2 A^{-}$ & $91.5 \pm 11.8$ & $94.4 \pm 8.9$ \\
${\text { mef } 2 A^{-\mathrm{FL}} / \mathrm{WT}}^{\mathrm{mef} 2 A^{-\mathrm{FL}} / \text { mef2A }^{-}}$ & $7.8 \pm 2.3$ & $5.3 \pm 2.1$ \\
\hline
\end{tabular}

The fluorescent cell population is indicated in the first column by the superscript FL for each 1:1 cell mixture. The average and standard deviations of 4 biological replicates are shown. was determined by the morphological changes observed under the microscope (Figure 6). Incubation of AX4 cells induced the differentiation of more that $90 \%$ of the cells into ellipsoid, highly refringent spores. However, when the mef $2 A^{-}$mutant cells were treated, the majority of the cells appeared rounded and flattened and very few (less than $5 \%$ ) refringent spores were observed (lower panel of Figure 6). Similar results were obtained for AX2 wild-type and mutant cells (data not shown).

\section{Gene expression profile of mef $2 A$ mutant cells}

We analyzed the differences in gene expression between AX4 and mef $2 A^{-}$strains after 16 hours of development (at the finger stage) when the difference in cell-type marker expression is greatest (see Figure 4). Poly(A) ${ }^{+}$RNAs were isolated, converted to cDNA and sequenced using an Illumina massive sequencing machine. A total of $14,847,781$ alignable sequences were obtained for the AX4 RNA and 11,809,110 for the mef2 $\mathrm{A}^{-} \mathrm{RNA}$, corresponding to approximately 13,500 different genes. The sequences 


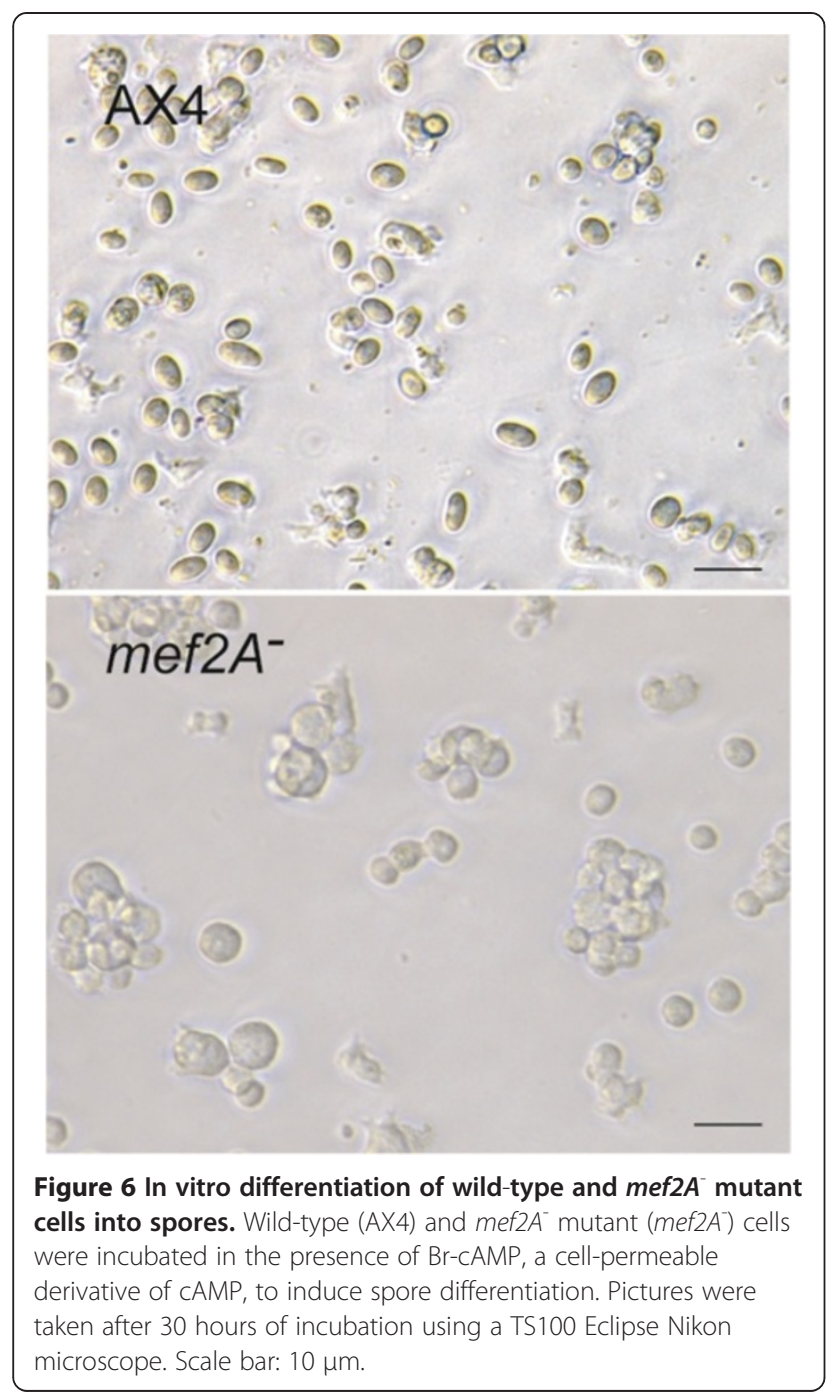

obtained were aligned over the AX4 genome sequence, and the number of sequences obtained for each gene was determined. The genes that presented a significant difference in the number of reads between wild-type and $m e f 2 A^{-}$ mutant strains were finally determined. Given that only one RNA sample was analyzed for each strain, stringent filters were used to determine the genes that were differentially expressed: more than 3 times in the number of reads, with an adjusted $p$ value of less than 0.01 . Seventy-seven genes showed significant differences with these criteria. Thirty two of these 77 genes showed higher expression in the wild-type strain, and 45 showed higher expression in the mef $2 A^{-}$mutant strain. As a control, the mef $2 A$ transcript was sequenced 73 times in the AX4 sample and none in the mutant sample. Table 3 shows the more significant genes that were found coding for known proteins or for proteins with a number of conserved domains. The largest group of genes code for small proteins that are expressed in prestalk cells and that are generally expressed to higher levels in the mef $2 A^{-}$mutant structures. A number of these genes showed similarity to the hss $A$ gene [33]. A second group of genes coded for 57-59 amino acid long proteins that do not show significant similarity to hss $A$ but are also expressed in prestalk cells. Three genes coding for small proteins (69-72 amino acid long) that were expressed in prespore cells showed lower expression in the $m e f 2 A^{-}$mutant structures. Other genes that are important for prestalk development and that were expressed at higher levels in the mef $2 A^{-}$mutant structures include Pks32, which codes for a polyketide synthase and could be involved in the synthesis of prestalk differentiation factors, and $m y b C$, which codes for a transcription factor involved in the response to prestalk differentiation factors [34]. A number of genes coding for proteins possibly involved in transcription regulation were identified. Their expression appears to be dependent on $m e f 2 A$ because the expression is significantly decreased in mutant structures.

To confirm and extend the data obtained, we performed quantitative RT-PCR experiments on new mRNAs isolated from structures collected after every two hours of development. The expression levels of 11 of the genes listed in Table 3 were determined by quantitative RT-PCR, and the results are shown in Figure 7. The genes selected were representative of the main categories identified in Table 3 and include two hssA-related genes (hssA, G0283503) and one gene coding for a small protein that was expressed at higher levels in the wild-type strain (G0285863). The other analyzed genes coded for proteins involved in prestalk differentiation $(P k s 32, m y b C)$, for proteins possibly involved in transcription regulation (G0290847, G0271438, mybC), for spore-inducing factors $(p s i)$ and for membrane proteins possibly involved in extracellular signaling or cell adhesion ( $\operatorname{tg} \mathrm{F} 1, \operatorname{tgrC5}, \mathrm{G0285697)}$. The results for these genes are in complete agreement with the mRNA sequencing data and show that the majority of these genes are similarly dependent on mef $2 A$ for all developmental times analyzed. The only exception was psiI, which was expressed at later developmental stages in the mef $2 A^{-}$mutant structures than in the wild-type structures (16 hours vs. 6 hours). The expression of several of the genes studied (G0285863, G0290847, G0271438, G0285697) was almost completely dependent on $m e f 2 A$ for all developmental stages analyzed.

\section{Discussion}

The study of the biological function of the mef $2 A$ gene was approached by generating deletion mutants in $D$. discoideum. Several mutants were generated in the AX2 and AX4 strains, and similar phenotypes were observed for all strains, as shown in Figure 3 and Tables 1 and 2. Over-expression of mef $2 A$ caused developmental defects that were morphologically similar to those observed in the mutants. Pools of $m e f 2 A$ over-expressing cells were similar to the mutant strains in the formation of more 
Table 3 Genes that showed a significant difference in their expression between wild-type and mef $2 A^{-}$mutant structures developed for 16 hours, as determined by mRNA sequencing

\begin{tabular}{|c|c|c|}
\hline & Increased expression in the mutant & Decreased expression in the mutant \\
\hline \multirow[t]{12}{*}{ hssA-related genes (prestalk-specific) } & G0267936 -93 (93-1) & G0293362 10.74 (26-279) \\
\hline & G0268400 -80 (160-2) & G0281013 11.95 (19-227) \\
\hline & G0277741 -55.6 (1724-31) & \\
\hline & G0281001 -31.2 (780-25) & \\
\hline & G0281189-134.75 (539-4) & \\
\hline & G0281191 0 (79-0) & \\
\hline & G0281195 -35.33 (106-3) & \\
\hline & G0281197 -55.5 (111-2) & \\
\hline & G0282307 -106.67 (320-3) & \\
\hline & G0283713 -72.75 (291-4) & \\
\hline & G0293356 -11.24 (281-25) & \\
\hline & hssA. -10 (1550-155) & \\
\hline \multirow[t]{15}{*}{ Small proteins (57-59 aa) (prestalk specific) } & G0283421 -34.33 (515-15) & \\
\hline & G0283465 -118.67 (356-3) & \\
\hline & G0283501 -25.19 (3929-156) & \\
\hline & G0283503 -41.42 (994-24) & \\
\hline & G0283505 -33.95 (1935-57) & \\
\hline & G0283507 -38.25 (1224-32) & \\
\hline & G0283511 -9.55 (2015-211) & \\
\hline & G0283515 -14.28 (2313-162) & \\
\hline & G0283519 -55.88 (950-17) & \\
\hline & G0272188 -15.28 (2119-139) & \\
\hline & G0269674 -15.57 (794-51) & \\
\hline & G0284283 (111-0) & \\
\hline & G0283395 (97-0) & \\
\hline & G0271888-40.5 (81-2) & \\
\hline & G0269672 -7.46 (574-77) & \\
\hline
\end{tabular}

Small proteins (69-72 aa) (prespore specific)

G0285863 28.07 (208-7523)

G0284623*C 35.48 (29-1029)

G0271110* $13.91(11-153)$

Tiger family proteins

Polyketide synthase family

Transcription regulation

Developmental genes

psiN -41.51 (5645-136)

Signaling proteins
St15 -7.69 (1084-171)

tgrF1. -39.85 (518-13)

Pks32-6.62 (1205-182)

mybC - $10.86(228-21)$

Omt12 -19.79 (277-14)

arrk -10.65 (213-20)
$\operatorname{tgrC5}{ }^{*} \mathrm{C} 18.9(10-189)$

$\mathrm{comH}^{*} \mathrm{ca} 11.53$ (184-2123)

G0288967* 17.07 (96-1639)

G0290847*a 21.74 (80-1739)

G0290855*C $32.39(41-1328)$

G0271438* 65.5 (4-262)

srfC. $0(0-73)$

psil 26.06 (469-12220)

hspC* ca 15.69 (26-408) 
Table 3 Genes that showed a significant difference in their expression between wild-type and mef $2 A^{-}$mutant structures developed for 16 hours, as determined by mRNA sequencing (Continued)

\begin{tabular}{|c|c|c|}
\hline \multirow[t]{2}{*}{ Metabolism } & osbH -38.33 (115-3) & fhbB 6.54 (525-3433) \\
\hline & G0278647 -23.43 (164-7) & \\
\hline \multirow[t]{5}{*}{ Putative Membrane proteins } & G0275535 -6.03 (3197-530) & G0285697* $451.2(5-2256)$ \\
\hline & G0289143 -9.79 (1116-114) & G0267564* $16.32(41-669)$ \\
\hline & G0287195 -10.05 (774-77) & G0272714* 10.99 (73-802) \\
\hline & G0284683 -11.87 (273-23) & G0270342* 10.81 (1679-18158) \\
\hline & & G0272042 8.53 (459-3915) \\
\hline \multirow[t]{2}{*}{ Translation regulation } & & Rpl32* 79.86 (7-559) \\
\hline & & R52*a 10.44 (195-2035) \\
\hline \multirow[t]{4}{*}{ Other functions } & G0277795 -23.55 (259.11) & G0284969* 12.87 (93-1197) \\
\hline & & $\operatorname{cog} 2^{*} 12.41(539-6687)$ \\
\hline & & G0276325* $32.62(8-261)$ \\
\hline & & G0290965*C 12.31 (13-160) \\
\hline
\end{tabular}

The following information is indicated in each line of columns 2 and 3: the reference number of the gene, the ratio of the number of reads in wild-type and mutant samples (negative when a larger number of reads was obtained for the mutant strain) and the actual number of reads for each sample (mutant-wild type). Asterisks on the third column indicate genes that present a sequence related to Mef2 binding sites in their putative promoter regions. The letter " $c$ " indicates that this sequence correspond to the consensus Mef2 binding site. The letter "a" indicates the presence of consensus binding sites for the $S$. cerevisiae Arg80 MADS-box transcription factor.

structures, more heterogeneous in size, and fewer slugs with reduced migration (data not shown), which prevented mutant complementation studies. Similar results were obtained when mef2A was expressed from integrative vectors using the constitutive Act15 promoter or the endogenous, prespore-specific mef $2 A$ promoter. A possible explanation for these results might be that over-expressed MefA proteins bind to co-factors or activating molecules outside the chromatin environment, thus impairing their regulatory function on DNA-bound Mef2A molecules.

The results indicate that $m e f 2 A$ is involved in the determination or differentiation of prespore cells and of a group of prestalk cells in $D$. discoideum. Mutant cells do not differentiate to spores in vitro and, in vivo, produce approximately half the number of spores than wild-type cells produce. These defects are cell-autonomous because the presence of wild-type cells is not able to induce differentiation of the mef $2 A^{-}$mutant cells. The proposed role would represent a conserved function for Mef2 proteins during evolution, given that plant and animal homologous proteins also play important roles in cell differentiation, as mentioned in the Introduction. Mef2A mutants also show impaired growth when feeding on bacteria. This defect does not appear to be due to a reduced phagocytic capacity, as determined by incubation with fluorescent microspheres (Fluoresbrite, PolySciences, data not shown). Differences in cell motility could also explain the smaller size of the colonies, but these possibilities have not been further studied. However, $m e f 2 A(s r f C)$ has been previously identified as one of the genes whose expression is regulated depending on the growth substrate of the $D$. discoideum cells, bacteria or axenic media [35].

As mentioned above, mef $2 A$ appears to be involved in the determination or differentiation of a population of prestalk cells located at the tip of the culminant structures and at the anterior-most region of the slugs. These cells express the $e c m B$ gene and include the tip-organizer cells that regulate the culmination of the structures [31]. The evidence for this function is that mef $2 A^{-}$mutant cells expressing ecmB::lac $Z$ do not participate in the formation of the tip in mixed developmental processes (Figure 5). In addition, mef $2 A$ mutant cells differentiate poorly to ecmBexpressing prestalk cells in vitro in the presence of DIF and cAMP [36] (data not shown). However, we have not detected $m e f 2 A$ expression in these cells. The cellautonomous function of mef $2 A$ during differentiation may be due to a cell-type determination process taking place at the previous mound stage of development where mef $2 A$ is expressed (Figure 2). Alternatively, the expression of $m e f 2 A$ in ecmB-expressing prestalk cells might be too low to be detected by gene reporter expression analyses.

Other populations of prestalk cells, however, are enlarged in mutant structures, as shown in Figure 4. Differences in cell type specification could explain the phenotypes observed. For example, the existence of a larger number of prestalk cells that adhere more strongly to each other might contribute to the breakage of the streams. In addition, a number of the genes that are misregulated in mef $2 \mathrm{~A}$ mutants, such as the $\operatorname{tg} r$ family of genes $(\operatorname{tg} r F 1, \operatorname{tg} r C 5)$, are involved in cell adhesion [37]. However, no differences in Ca-dependent cell adhesion could be determined 


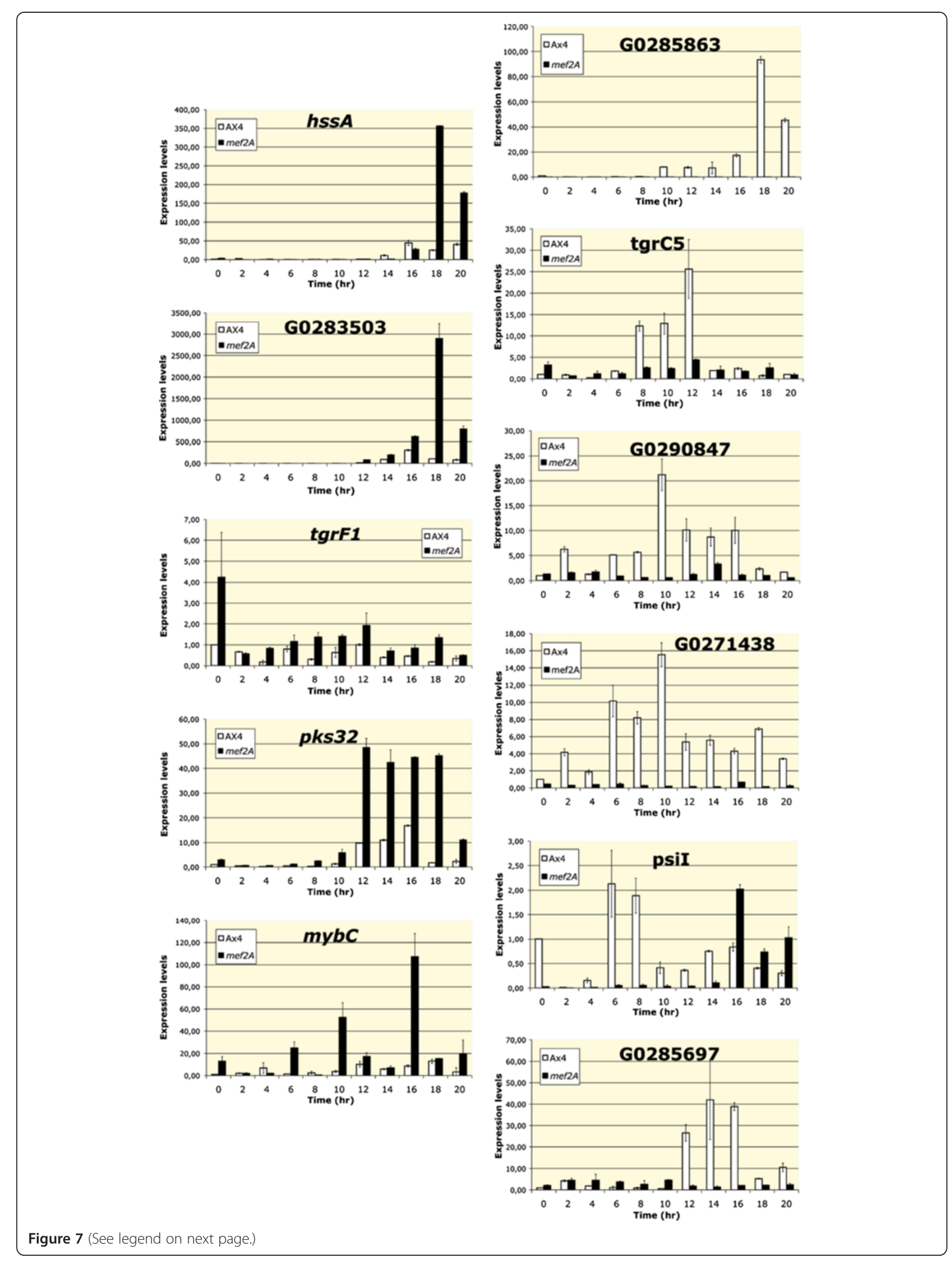


(See figure on previous page.)

Figure 7 Developmental expression pattern of representative genes differentially regulated in wild-type and mef2A mutant structures, as determined by mRNA sequencing. RNA was isolated from wild-type (AX4) or mef2A- mutant (mef2A) cells during growth (time 0) or from structures developed for the indicated times on nitrocellulose filters (2-20 hours). RNAs were converted into cDNA, and the expression level of each gene was determined by quantitative PCR. A fragment of the large mitochondrial ribosomal RNA was used as an internal control for expression quantification. The relative value of 1 was assigned to the expression level of growing wild-type cells for each gene. Open bars correspond to the wild-type expression levels and black bars to the mef2A- mutant expression levels. Panels on the left correspond to genes that were expressed at the highest levels in mef $2 A^{-}$mutant structures, according to the mRNA sequencing analyses, and the panels on the right correspond to genes that were expressed at higher levels in wild-type cells. Two biological replicates and three technical replicates of each sample were analyzed. Error bars represent the standard deviation of the data. experimentally using the method described by Parkinsons et al. [38] (data not shown). The slug structures also showed a highly altered proportion and distribution of prestalk and prespore cells (Figure 4), which could explain their smaller size and limited motility.

Despite the developmental defects discussed above, it seems clear that mef $2 A$ is not absolutely required for $D$. discoideum development given that a large number of fruiting bodies and spores are formed in the mutant strains. We would like to suggest that $m e f 2 A$ participates in a network of transcription factors that regulate cell differentiation and that could compensate, at least partially, for the absence of $m e f 2 A$. For example, mutations of histone deacetylases [39] and chromatin-binding proteins [40] affect prespore differentiation or cell-type patterning. In addition, the expression of several genes coding for putative transcriptional regulators is regulated by mef $2 A$. For example, comH codes for a GATA-binding transcription factor expressed in prespore cells. G0288967 codes for a putative $\beta$-sandwich domain transcription factor, and G0290847, G0290855 and G0271438 code for proteins containing domains possibly involved in DNA binding and transcription regulation. $r b l A$, a retinoblastoma homolog, also controls the preference of the cells for stalk or spore differentiation [41]. This gene is expressed in the prespore region, and, in chimera with wild-type cells, $r b l A$ mutant cells show a strong preference for stalk differentiation, as was also demonstrated here for mef $2 A$ mutants.

Mef2A might play a cell-autonomous regulatory role in cell differentiation in response to extracellular signals analogous to those described in other biological systems. The activity of vertebrate Mef2 transcription factors is tightly regulated by extracellular signals. One of the best-known regulatory pathways involves the regulated association of Mef2 with class II histone deacetylases in a process mediated by protein phosphorylation [42]. Mef2 can also be directly phosphorylated through MAP kinase pathways, regulating its transcriptional activity [43]. In this respect, the $D$. discoideum MAP kinase ErkB is required for spore differentiation $[44,45]$. It would be of interest to determine whether mef $2 A$ participates in this ErkB-mediated spore differentiation pathway, especially given that Mef2A presents three consensus ERK phosphorylation sites.
The main regulatory pathway described as inducing prespore cell differentiation is initiated by extracellular CAMP and requires protein kinase A (PKA) activation [46]. The in vitro spore differentiation study shown in Figure 6 was induced by Br-cAMP treatment, resulting in direct PKA activation. The $m e f 2 A^{-}$mutant cells were unable to differentiate under these conditions. This result indicates that Mef2A regulation takes place downstream of PKA. In fact, a PKA consensus phosphorylation site is present close to the $\mathrm{C}$-terminal end of Mef-2, indicating the possibility that this protein might be a substrate for PKA.

Massive-sequencing analyses of gene expression indicate that Mef2A can play a role in cell differentiation through the regulation of gene expression. There are 32 genes whose expression decreases in mef $2 A$ mutants, and many of these genes are specifically expressed in prespore cells, as determined by the mRNA expression analysis available at Dictybase (DictyExpress [47]) and by the in situ hybridization analysis [48]. A number of prespore specific proteins, often used as prespore markers, also showed differences in expression between AX4 and the mef $2 A$ mutant strain but did not reach the filter requirements set up in the analysis of the sequencing data (more than 3 times the difference in the expression level and a p-value smaller than 0.01). For example, $\cot A$ was expressed 2.12 more times in AX4 than in the mutant, $\cot C$ was expressed 2.02 times, cotD 1.48 times, $p s p D 1.95$ times, $p s p B 2.52$ times and $p s p A$ 1.39 times. In contrast, many of the genes that are overexpressed in the mef $2 A$ mutant have been identified as prestalk-specific, as shown in Table 3. The prestalk-specific gene ecmA was also expressed at higher levels in the mutant (1.51 times). However, ecmB was expressed 1.53 times more in AX4, in agreement with the reduced and more disorganized distribution of ecmB-expressing cells in the mutant at 16 hours of development (Figure 4).

Further studies are required to determine the mechanism involved in the transcriptional regulation of the genes whose expression is altered in mef $2 A$ mutants. Several of the genes that are under-expressed in mef $2 A$ mutants appear to be almost completely dependent on this transcription factor for their expression. The regulation of the expression of these genes could be mediated by the direct binding of Mef2A to their regulatory regions. The DNA 
binding site of Mef2-related factors has been conserved through evolution and corresponds to the consensus sequence $\mathrm{CTA}(\mathrm{A} / \mathrm{T})_{4} \mathrm{ATG}$. We looked for the presence of this sequence on the 1000 nucleotide-long fragments located upstream of the 21 genes down-regulated in the mutant using the oPOSSUM program [49]. As shown in Table 3, 6 of these genes contained this consensus sequence in the region analyzed. Thirteen additional genes contained related sequences that differed in the $\mathrm{C}$ or the $\mathrm{G}$ nucleotides. In addition, 4 genes presented the consensus binding site of a related MADS-box transcription factor (ARG80 from S. cerevisiae) [50]. These data indicate that a number of these genes could be direct regulatory targets of Mef2A. Alternatively, mef $2 A$ could regulate the expression of other transcription factors controlling the expression of these genes.

The initial analysis of the structure of the mef $2 \mathrm{~A}$ gene detected the existence of alternative promoters that drive the expression of the gene at different times of development and in distinct structures. It is remarkable that the related $s r f A$ and $s r f B$ genes are also transcribed from alternative promoters, specific for different cell types and developmental stages [30,51]. Other developmental regulatory genes are also transcribed from alternative promoters in $D$. discoideum, such as $p d s A$ (extracellular phosphodiesterase) [52] carA (cAMP receptor) [53] and acaA (adenylyl cyclase A) [54]. The existence of alternative promoters might have been an evolutionary adaptation that regulates the expression of a gene under different conditions of growth and/or different developmental processes.

\section{Conclusions}

$m e f 2 A$, which codes for a protein homologous to myocyte enhancer factor 2 transcription factors, is required for several of the steps of the $D$. discoideum biological cycle, including growth on bacteria and multicellular development. In particular, mef $2 \mathrm{~A}$ is involved in the regulation of the determination or differentiation of prespore cells and a group of prestalk cells during the developmental process of fruiting body formation.

\section{Methods}

\section{Cell culture, transformation and development}

D. discoideum cells were cultured axenically in HL5. Transformation by electroporation was performed as described previously [55]. Transformed cells were selected by treatment with blasticidin [56] or neomycin (G418). Filter development was induced by spreading $1-2 \times 10^{7}$ cells $\left(0.6-1.2 \times 10^{6}\right.$ cells $\left./ \mathrm{cm}^{2}\right)$ on nitrocellulose filters (Millipore Co., Bradford, MA, USA) [57]. The phosphate-based PDF buffer was used to obtain finger, Mexican-hat and culminant structures. Slug structures were obtained by conducting the development in water-soaked filters under directional light. Submerged development was induced by incubation of the cells in $2 \mathrm{ml}$ of PDF phosphate-based buffer on $37-\mathrm{mm}$ diameter cell-culture dishes at $5 \times 10^{5}$ cells $/ \mathrm{ml}$.

\section{Phylogenetic studies}

The amino acid sequences of MADS-box regions from various organisms were obtained from public databases and compared to those of the four $D$. discoideum proteins containing MADS-box-related sequences, obtained from DictyBase (http://www.dictybase.org). Amino acid sequences were compared using the ClustalW program at the online Biology Workbench facilities from the San Diego Supercomputer Center (http://workbench.sdcs.edu) and the ClustalX program [58]. Phylogenetic trees were determined using the neighbor-joining method [59]. A random generator seed of 111 and 1000 bootstrap trials were calculated. Trees were drawn using the NJplot program.

\section{Rapid amplification of cDNA ends}

RNA was isolated from AX4 cells at 8 hours of multicellular development on nitrocellulose filters. The SMART ${ }^{\mathrm{TM}}$ cDNA amplification kit from Clontech (Clontech Laboratories, Inc, Mountain View, CA, USA) was used for the amplification of the $5^{\prime}$ untranslated region of mef $2 A$ mRNA according to the manufacturer's instructions. The oligonucleotide TGTTGCCTGTCTATTTCTTTCATTAG, complementary to nucleotides 145 to 164 of the gene, was used as the primer. Amplification products were cloned in the pGEM $^{\circledR}$-T Easy Vector System (Promega Co, Madison, WI, USA), and the insert of at least 10 different colonies of each product were sequenced.

\section{Determination of mef $2 A$ expression by RT-PCR}

RNA was isolated from $2 \times 10^{7}$ cells, either during growth or after development on nitrocellulose filters for 2 to 24 hours, using the TRI reagent (Sigma-Aldrich Inc., St. Louis, MO, USA) according to the manufacturer's instructions. RNA was further purified using the RNeasy Mini Kit (Quiagen). cDNAs were generated from $2 \mu \mathrm{g}$ of total RNA using gene-specific oligonucleotides as primer. cDNAs were used as substrates for PCR reactions using as primers the oligonucleotides used for cDNA synthesis and upstream oligonucleotides designed from the coding region of the transcripts. The oligonucleotides GGACTAGTTTCCATT GAACCAATTGGGTGAGCG and CTGATAATACAGAT AATACTCGC were used for mef $2 A$ cDNA synthesis. The large mitochondrial rRNA was amplified as a control, using oligonucleotides GGGTAGTTTGACTGGGGCGG and CACTTTAATGGGTGAACACC.

\section{Vectors for the generation of knockout strains}

Flanking regions of the $m e f 2 A$ gene, including nucleotides -4069 to -2692 and 596 to 1298 , in relation to the A of the translation initiation codon were generated by PCR and cloned on both sides of the blasticidin 
resistance gene in the pLPBLP plasmid vector [60]. The ligonucleotides GGCCGCGGCCATTCCCAGCAACGCT GGTAATC, GGTCTAGACCTGGAAAACTGGAAAACC AATTG, GGATCGATCCACCCACACTAACACACACC and GGGTCGACGGTGGTGGTGATTGGTGCTG were used for these amplifications. The oligonucleotides TGG GAAGGAATAAAATTACAATTGAAAAG and GCGAG TATTATCTGTATTATCAG were used to test for the deletion in AX4 strains, and GTTGCCTGTCTATTTCTTTC and CACTCACTTACATATCACACACC were used in AX2 strains.

\section{Construction of the reporter and expression vectors}

The two mef2A promoter regions were amplified by PCR from $D$. discoideum genomic DNA and cloned in the reporter vector PsA-ialphaGal [61] in substitution of the $\mathrm{XbaI} / \mathrm{BglII} p s p A$ promoter fragment. The oligonucleotides GGTCTAGAGCACAAGATTATACTTGCCA and GGA GATCTCATGGTGTGTGATATGTAAGTGAGTG were used to amplify the -2201 to -489 region of the gene, corresponding to Promoter 1. The oligonucleotides GGTCTAGACACTCACTTACATATCACACACC and GGAGATCTTGTTGCCTGTCTATTTCTTTCATTAG were used to amplify the -511 to 164 region, corresponding to Promoter 2. The complete promoter region $(-2201$ to 164) was amplified using the first and last oligonucleotides described above. Previously described lac $Z$ reporter vectors were used to determine the expression of the developmental markers $p s p A$ [61], ecmA and ecmB [62].

The mef $2 A$ gene was expressed using the pDVCGFP-CTAP vector [63], under control of the Actin15 promoter. The region coding amino acids 4 to 1046 of the protein, including the third intronic region of the gene, was amplified from genomic DNA using the Pfx DNA Polymerase (Invitrogene ${ }^{\mathrm{TM}}$ ). Two overlapping fragments were obtained using the oligonucleotide pairs GGATCCAGGAATAAAATTACAATTGAAAAG/ GGAGATTGATGCTGTGGTTG and CAACAACAAAG CGCCAATCC/ACTAGTAGGTTCCATTGATTTTCTTT TTCGG. The two fragments were joined together using the overlapping HaeII restriction site and the resultant fragment cloned between the BamHI and SpeI restriction sites of the vector. A second expression vector where mef $2 A$ was expressed under control of his own promoter was constructed by substituting the Actin 15 promoter of the pDV-CGFP-CTAP/mef $2 A$ vector by the $m e f 2 A$ promoter. The Actin 15 promoter was excised by SalI and BamHI digestion and replaced by the complete mef $2 A$ promoter previously cloned in the PsA-ialphaGal vector, as described above. The mef $2 A$ promoter was isolated by $\mathrm{XbaI} /$ BglII digestion. The SalI end of the vector and the $\mathrm{XbaI}$ end of the promoter were converted to blunt ends before ligation.

\section{Histochemistry and determination of $\beta$-galactosidase activity in developmental structures}

Cells transformed with the different reporter vectors were allowed to develop on nitrocellulose filters for the time periods indicated in each experiment. The structures were fixed and permeabilized, and $\beta$-galactosidase activity was detected by hydrolysis of X-gal (5-Bromo-4chloro-3-indolyl $\beta$-D-galactopyranoside), as previously described [64].

\section{Cell tracking experiments}

Growing cells were collected by centrifugation and resuspended in phosphate-based PDF buffer containing $5 \mu \mathrm{l} / \mathrm{ml}$ of $100 \mathrm{mM}$ CellTracker ${ }^{\mathrm{TM}}$ Blue CMHC (4chloromethyl-7-hydroxycoumarin) (Invitrogen, Eugene, Oregon, USA) or a vehicle (DMSO) and incubated for 1 hour in shaking cultures. Cells were then washed, resuspended in free PDF buffer and mixed in a 1:1 proportion. A total of $6.6 \times 10^{6}$ cells from each mixture were spread out on nitrocellulose filters for 24-36 hours, after which several sori from each mixture were harvested and dissociated in water. Spores were visualized in a Zeiss Axiophot fluorescence microscope and counted.

\section{Determination of mRNA levels by quantitative RT-PCR}

RNA was isolated from $2 \times 10^{7}$ cells, either during growth or after development on nitrocellulose filters for the times indicated in each experiment, using the TRI reagent (Sigma-Aldrich Inc., St. Louis, MO, USA) according to the manufacturer's instructions. RNA was further purified using the RNeasy Mini kit (Quiagen). cDNAs were generated from $2 \mu \mathrm{g}$ of total purified RNA using random primers (Promega Co., Madison, WI, USA). cDNAs were used as substrate for quantitative real-time PCR reactions using the following gene-specific oligonucleotides: hss $A$ gene (DDB_G0280999) GTGCTATTACCTCAATTTCAAG and GGCAACCACATGAACCACTTG; DDB_G0283503 gene CAAATCATTACAATCAATCACAAGTG and GGGCTA CAGCAGCAACTG; prS1 gene (DDB_G0285863) CCAA TAATTCTTTGAAGGCCC and CAATAGCTTGGCCC ATAGTAGC; $\operatorname{tgr} F 1$ gene (DDB_G0292732) CCCACCA TTTACTCCAATACTC and GTAGAGATGGTGTTGAT GGAG; $\operatorname{tgr} C 5$ gene (DDB_G0281407) GCTGGCTTAGC ACTTTCATCAG and GAGACCAACGGCAGCGACAC; pks32 gene (DDB_G0292732) CAACTCCAGTCACAA CTATAGC and GATTATCATGAATGTGGAATGCTG; $m y b C$ gene (DDB_G0281563) GGTGGAGGTAAAACTG GTGC and CATCCATCCAACTAATATCACG; DDB_G 0290847 gene CAGTACTGAACAAGCATTATCAAG and GTTAACATAACCTTGTTGAGAATC; DDB_G0271438 gene GTCATGAAATTGGAGATCGAAG and CATGAGA TGATGTTGATTTGG; psiI gene (DDB_G0288919) GGT TGTACACTTGTACCACG and GAGGTGCTTCAAAG AGAGC; DDB_G0285697 gene GGTAAGGCAGTTGTC 
AATGC and GCCTACCAGCTGAGACTTCAGC. A region of the large mitochondrial ribosomal RNA was amplified as a loading control using the oligonucleotides CACTTTAATGGGTGAACACC (used as a reverse oligonucleotide) and GGGTAGTTTGACTGGGGCGG (used as a forward oligonucleotide). The StepOnePlus Real-Time PCR System (Life Technologies Co., Applied Biosystems, Carlsbad, CA, USA) was used in these experiments. PCR products were labeled with SYBR Green using the Power $\mathrm{SYBR}^{\circledR}$ Green PCR Master Mix reaction mix (Applied Biosystems) following the manufacturer's instructions. The final volume of the reaction was $20 \mu \mathrm{l}$, using a $0.2 \mu \mathrm{M}$ concentration of each primer. PCR conditions were as follows: $95^{\circ} \mathrm{C}, 10 \mathrm{~m} ;\left(95^{\circ} \mathrm{C}, 15 \mathrm{~s} ; 45^{\circ} \mathrm{C}, 30 \mathrm{~s} ; 62^{\circ} 1 \mathrm{~m}\right) \times 30-40$ cycles.

\section{In vitro spore differentiation}

Exponentially growing cells were washed in KK2 buffer (16.5 mM KH $\mathrm{KH}_{2}, 3.9 \mathrm{mM} \mathrm{K} \mathrm{POPO}_{4}, 2 \mathrm{mM} \mathrm{MgSO}$, $\mathrm{pH}$ 6.2), plated on culture dishes at a concentration of $10^{6}$ cells $/ \mathrm{ml}$ in spore buffer (10 mM MOPS, $20 \mathrm{mM}$ $\mathrm{KCl}, 20 \mathrm{mM} \mathrm{NaCl}, 1 \mathrm{mM} \mathrm{CaCl}, 1 \mathrm{mM} \mathrm{MgCl}$, $\mathrm{pH}$ 6.2) and supplemented with $12.5 \mathrm{mM} 8$-Br-cyclic-AMP and $20 \mu \mathrm{M} \mathrm{CdCl}_{2}$ [32,65]. Cells were incubated in the dark for 30 hours and then observed under a TS100 Eclipse Nikon microscope (Nikon, Tokyo, Japan). Pictures were taken with a Leica DFC420 camera (Leica Microsystems, Wetzlar, Germany).

\section{mRNA sequencing}

RNA was isolated from structures developed on nitrocellulose filters for 16 hours using the TriReagent and purified with an RNeasy Mini kit, as described previously. Poly (A)-containing RNA was isolated and converted to cDNA. The cDNA was fragmented, amplified by PCR and the nucleotide sequences determined using an Illumina Genome Analyzer IIx massive sequencer at the Parque Científico de Madrid. Sequencing data were analyzed at Sistemas Genómicos, S.L. (Valencia, Spain). The generated sequences were mapped to the D. discoideum genome using the TopHat v1.1.3 software [66]. Transcripts were identified and quantified using the Cufflinks v1.0.3 program. The total number of reads per gene was determined using the HTSeq package (http://www-huber.embl.de). Statistical analyses of the results was performed using the DESeq package [67], using an FDR of 0.01. A minimal difference of three times in expression levels was considered.

\section{Additional file}

Additional file 1: Figure S1. Comparative study of the amino acid sequences of the $D$. discoideum MADS-boxcontaining proteins. Panel A. The functional and structural domains present in the D. discoideum SrfC (Mef2A) protein are schematically shown. M: MADS-box; m: Mef2-conserved domain;
$\mathrm{N}$ : Polyasparagine tract; Q: Polyglutamine tract. Panel B. The amino acid sequences of the MADS-box domains (amino acids 1 to 60 of the SifC sequence) and the contiguous SRF- or Mef2-specific domains (amino acids 61 to 86 ) of the species indicated on the left are aligned in relation to the $D$. discoideum SrfC (Mef2A) sequence using the Clustal W program. Darker boxes indicate the presence of 8 or more identical amino acids. Lighter boxes indicate the existence of 8 or more amino acids with similar chemophysical characteristics. Figure S2. Analysis of the structure of the $5^{\prime}$ region of the $m e f 2 A$ gene and determination of the transcription start sites. The sequence of the $5^{\prime}$ region of the mef $2 A$ mRNA was determined by primer extension using the rapid amplification of the CDNA ends (RACE) technique. The sequences obtained were aligned with the genomic DNA sequence to determine the intron/exon structure of this region of the gene and the transcription initiation sites [GenBank:KC852901]. Exon regions are indicated in black capital letters while intron sequences are indicated in blue small letters. Consensus splicing sites are underlined. The sequence is numbered from the Adenine of the translation initiation codon, shown in bold characters. Transcription initiation sites, as determined by RACE, are indicated with red asterisks over the nucleotide sequence. The complete sequence of the third intron of the gene and the sequence of the large fourth exon, coding for the C-terminal region of the protein, are not shown but are schematically indicated on Figure 2 .

\section{Competing interests}

The authors declare that they have no competing interest in the publication of this manuscript.

\section{Authors' contributions}

MG-C performed the experiments on gene expression and the characterization of the mutant strain and participated in the draft of the manuscript. IF-A characterized the promoter region and generated the mutant strains. TS performed the in vitro differentiation experiments and participated in the draft of the manuscript. LS conceived the study and participated in its design and coordination, as well as the drafting of the manuscript. All authors read and approved the final manuscript.

\section{Acknowledgements}

The authors are indebted to the Dictybase organization for information and reagents. The collaboration of the Parque Cientifico de Madrid with RNA sequencing experiments is also acknowledged. LS was funded by grant BFU2008-02249 from the Spanish Ministry of Science and Innovation (Ministerio de Ciencia e Innovacion). MGC was supported by a JAE predoctoral fellowship from the High Council on Scientific Research (Consejo Superior de Investigaciones Cientificas). We acknowledge the financial support for publication by the CSIC Open Access Publication Support Initiative through its Research Information Resources Unit (URICI).

\section{Author details}

${ }^{1}$ Instituto de Investigaciones Biomédicas de Madrid (Biomedical Research Institute of Madrid), CSIC/UAM, C/Arturo Duperier 4, 28029, Madrid, Spain. ${ }^{2}$ Centro de Investigaciones Biologicas (Biological Research Center), CSIC, C/Ramiro de Maeztu, 9, 28040, Madrid, Spain.

Received: 14 November 2012 Accepted: 5 April 2013 Published: 11 April 2013

\section{References}

1. Theiben G, Kim JT, Saedler H: Classification and Phylogeny of the MADS-box Multigene Family Suggest Defined Roles of MADS-box Gene Subfamilies in the Morphological Evolution of Eukaryotes. $J$ mol evol 1996, 43:484-516.

2. Gramzow $L$, Ritz MS, Theissen G: On the origin of MADS-domain transcription factors. Trends Genet 2010, 26(4):149-153.

3. Shore P, Sharrocks AD: The MADS-box family of transcription factors. Eur $J$ Biochem 1995, 229(1):1-13.

4. Treisman R: DNA-binding proteins. Inside the MADS box. Nature 1995, 376(6540):468-469.

5. Becker A, Theissen G: The major clades of MADS-box genes and their role in the development and evolution of flowering plants. Mol Phylogenet Evol 2003, 29(3):464-489. 
6. Messenguy F, Dubois E: Role of MADS box proteins and their cofactors in combinatorial control of gene expression and cell development. Gene 2003, 316:1-21.

7. Pollock R, Treisman R: A sensitive method for the determination of protein-DNA binding specificities. Nucleic Acids Res 1990, 18(21):6197-6204.

8. Sun Q, Chen G, Streb JW, Long X, Yang Y, Stoeckert CJ Jr, Miano JM: Defining the mammalian CArGome. Genome Res 2007, 16:197-207.

9. Black BL, Olson EN: Transcriptional control of muscle development by myocyte enhancer factor-2 (MEF2) proteins. Annu Rev Cell Dev Biol 1998, 14:167-196

10. Treisman R, Ammerer G: The SRF and MCM1 transcription factors. Curr Opin Genet Dev 1992, 2(2):221-226.

11. Chang VK, Donato JJ, Chan CS, Tye BK: Mcm1 promotes replication initiation by binding specific elements at replication origins. $\mathrm{Mol} \mathrm{Cell} \mathrm{Biol}$ 2004, 24:6514-6524

12. Schratt G, Philippar U, Berger J, Schwarz H, Heidenreich O, Nordheim A: Serum response factor is crucial for actin cytoskeletal organization and focal adhesion assembly in embryonic stem cells. J Cell Biol 2002, 156:737-750.

13. Arsenian S, Weinhold B, Oelgeschlager M, Ruther U, Nordheim A: Serum response factor is essential for mesoderm formation during mouse embryogenesis. Embo J 1998, 17(21):6289-6299.

14. Miano JM: Role of serum response factor in the pathogenesis of disease. Lab Invest 2010, 90(9):1274-1284.

15. Miano JM, Long X, Fujiwara K: Serum response factor: master regulator of the actin cytoskeleton and contractil apparatus. Am J Physiol Cell Physiol 2007, 292:C70-C81.

16. Olson EN, Nordheim A: Linking actin dynamics and gene transcription to drive cellular motile functions. Nat Rev Mol Cell Biol 2010, 11(5):353-365.

17. Sandmann T, Jensen $L$, Jakobsen JS, Karzynski MM, Eichenlaub MP, Bork P, Furlong EE: A temporal map of transcription factor activity: mef2 directly regulates target genes at all stages of muscle development. Dev Cell 2006, 10(6):797-807.

18. Naya FJ, Olson E: MEF2: a transcriptional target for signaling pathways controlling skeletal muscle growth and differentiation. Curr Opin Cell Biol 1999, 11(6):683-688.

19. Molkentin JD, Olson EN: Combinatorial control of muscle development by basic helix-loop-helix and MADS-box transcription factors. Proc Natl Acad Sci U S A 1996, 93(18):9366-9373.

20. McKinsey TA, Zhang CL, Olson EN: MEF2: a calcium-dependent regulator of cell division, differentiation and death. Trends Biochem Sci 2002, 27(1):40-47.

21. Lin Q, Schwarz J, Bucana C, Olson EN: Control of mouse cardiac morphogenesis and myogenesis by transcription factor MEF2C. Science 1997, 276(5317):1404-1407.

22. Naya FJ, Black BL, Wu H, Bassel-Duby R, Richardson JA, Hill JA, Olson EN: Mitochondrial deficiency and cardiac sudden death in mice lacking the MEF2A transcription factor. Nat Med 2002, 8(11):1303-1309.

23. Potthoff $M$, Olson EN: MEF2: a central regulator of diverse developmental programs. Development 2007, 134:4131-4140.

24. Arnold MA, Kim Y, Czubryt MP, Phan D, McAnally J, Qi X, Shelton JM, Richardson JA, Bassel-Duby R, Olson EN: MEF2C transcription factor controls chondrocyte hypertrophy and bone development. Dev Cell 2007, 12(3):377-389.

25. Williams JG: Dictyostelium finds new roles to model. Genetics 2010, 185(3):717-726.

26. Schaap P: Evolutionary crossroads in developmental biology: Dictyostelium discoideum. Development 2011, 138(3):387-396.

27. Urushihara $\mathrm{H}$ : Social amoeba and the origin of multicellularity. Dev Growth Differ 2011, 53(4):451.

28. Escalante R, Sastre L: A serum response factor homolog is required for spore differentiation in Dictyostelium. Development 1998, 125:3801-3808.

29. Escalante R, Yamada Y, Cotter D, Sastre L, Sameshima M: The MADS-box transcription factor SrfA is required for actin cytoskeleton organization and spore coat stability during Dictyostelium sporulation. Mechanisms of Development 2004, 121(1):51-56.

30. Galardi-Castilla M, Pergolizzi B, Bloomfield G, Skelton J, Ivens A, Kay RR, Bozzaro S, Sastre L: SrfB, a member of the Serum Response Factor family of transcription factors, regulates starvation response and early development in Dictyostelium. Dev Biol 2008, 316(2):260-274.
31. Williams JG: Transcriptional regulation of Dictyostelium pattern formation. EMBO Rep 2006, 7(7):694-698.

32. Kay RR: Evidence that elevated intracellular cyclic AMP triggers spore maturation in Dictyostelium. Development 1989, 105:753-759.

33. Shimada N, Kanno-Tanabe N, Minemura K, Kawata T: GBF-dependent family genes morphologically suppress the partially active Dictyostelium STATa strain. Dev Genes Evol 2008, 218(2):55-68.

34. Guo K, Anjard C, Harwood A, Kim HJ, Newell PC, Gross JD: A myb-related protein required for culmination in Dictyostelium. Development 1999, 126:2813-2822.

35. Sillo A, Bloomfield G, Balest A, Balbo A, Pergolizzi B, Peracino B, Skelton J, Ivens A, Bozzaro S: Genome-wide transcriptional changes induced by phagocytosis or growth on bacteria in Dictyostelium. BMC Genomics 2008, 9:291.

36. Jermyn KA, Berks M, Kay RR, Williams JG: Two distinct classes of prestalkenriched mRNA sequences in Dictyostelium discoideum. Development 1987, 100:745-755.

37. Benabentos R, Hirose S, Sucgang R, Curk T, Katoh M, Ostrowski EA, Strassmann JE, Queller DC, Zupan B, Shaulsky G, et al: Polymorphic members of the lag gene family mediate kin discrimination in Dictyostelium. Curr Biol 2009, 19(7):567-572.

38. Parkinson K, Bolourani P, Traynor D, Aldren NL, Kay RR, Weeks G, Thompson CR: Regulation of Rap1 activity is required for differential adhesion, cell-type patterning and morphogenesis in Dictyostelium. J Cell Sci 2009, 122(Pt 3):335-344.

39. Sawarkar R, Visweswariah SS, Nellen W, Nanjundiah V: Histone deacetylases regulate multicellular development in the social amoeba Dictyostelium discoideum. J Mol Biol 2009, 391(5):833-848

40. Dubin MJ, Kasten S, Nellen W: Characterization of the Dictyostelium homolog of chromatin binding protein DET1 suggests a conserved pathway regulating cell type specification and developmental plasticity. Eukaryot Cell 2011, 10(3):352-362.

41. MacWilliams H, Doquang K, Pedrola R, Dollman G, Grassi D, Peis T, Tsang A, Ceccarelli A: A retinoblastoma ortholog controls stalk/spore preference in Dictyostelium. Development 2006, 133(7):1287-1297.

42. Miska EA, Karlsson C, Langley E, Nielsen SJ, Pines J, Kouzarides T: HDAC4 deacetylase associates with and represses the MEF2 transcription factor. EMBO J 1999, 18(18):5099-5107.

43. Han J, Jiang Y, Li Z, Kravchenko W, Ulevitch RJ: Activation of the transcription factor MEF2C by the MAP kinase p38 in inflammation. Nature 1997, 386(6622):296-299.

44. Nguyen HN, Hadwiger JA: The Galpha4 G protein subunit interacts with the MAP kinase ERK2 using a D-motif that regulates developmental morphogenesis in Dictyostelium. Dev Biol 2009, 335(2):385-395.

45. Nguyen HN, Raisley B, Hadwiger JA: MAP kinases have different functions in Dictyostelium G protein-mediated signaling. Cell Signal 2010, 22(5):836-847.

46. Mann SKO, Richardson DL, Lee S, Kimmel AR, Firtel RA: Expression of CAMP-dependent protein kinase in prespore cells is sufficient to induce spore cell differentiation in Dictyostelium. Proc Natl Acad Sci USA 1994, 91:10561-10565

47. Loomis WF, Shaulsky G: Developmental changes in transcriptional profiles. Dev Growth Differ, 53(4):567-575.

48. Maruo T, Sakamoto H, Iranfar N, Fuller D, Morio T, Urushihara H, Tanaka Y, Maeda M, Loomis WF: Control of cell type proportioning in Dictyostelium discoideum by differentiation-inducing factor as determined by in sity hybridization. Euk Cell 2004, 3(5):1241-1248.

49. Ho Sui SJ, Mortimer JR, Arenillas DJ, Brumm J, Walsh CJ, Kennedy BP, Wasserman WW: oPOSSUM: identification of over-represented transcription factor binding sites in co-expressed genes. Nucleic Acids Res 2005, 33(10):3154-3164.

50. Chen G, Hata N, Zhang MQ: Transcription factor binding element detection using functional clustering of mutant expression data. Nucleic Acids Res 2004, 32(8):2362-2371.

51. Escalante R, Vicente JJ, Moreno N, Sastre L: The MADS-box gene srfA is expressed in a complex pattern under the control of alternative promoters and is essential for different aspects of Dictyostelium development. Dev Biol 2001, 235(2):314-329.

52. Faure M, Franke J, Hall AL, Podgorski GJ, Kessin RH: The cyclic nucleotide phosphodiesterase gene of Dictyostelium discoideum contains 3 promoters specific for growth, aggregation, and late development. Mol Cell Biol 1990, 10:1921-1930. 
53. Louis JM, III Saxe CL, Kimmel AR: Two transmembrane signaling mechanisms control expression of the CAMP receptor gene CAR1 during Dictyostelium development. Proc Natl Acad Sci USA 1993, 90:5969-5973.

54. Galardi-Castilla M, Garciandia A, Suarez T, Sastre L: The Dictyostelium discoideum acaA gene is transcribed from alternative promoters during aggregation and multicellular development. PLoS One 2010, 5(10):e13286.

55. Pang KM, Lynes MA, Knecht DA: Variables controlling the expression level of exogenous genes in Dictyostelium. Plasmid 1999, 41:187-197.

56. Adachi $\mathrm{H}$, Hasebe $T$, Yoshinaga $\mathrm{K}$, Ohta T, Sutoh $\mathrm{K}$ : Isolation of Dictyostelium discoideum cytokinesis mutants by restriction enzyme-mediated integration of the blasticidin $\mathrm{S}$ resistance marker. Biochem Biophys Res Commun 1994, 205:1808-1814.

57. Shaulsky G, Loomis WF: Cell type regulation in response to expression of ricin-A in Dictyostelium. Dev Biol 1993, 160:85-98.

58. Thompson J, Gibson T, Plewniak F, Jeanmougins F, Higgins D: The ClustalX windows interface: flexible strategies for multiple sequence alignment aided by quality analysis tools. Nucl Acids Res 1997, 25:4876-4882.

59. Saitou N, Nei M: The Neighbor-Joining method for reconstructing phylogenetic trees. Mol Biol Evol 1987, 4:406-425.

60. Faix J, Kreppel L, Shaulsky G, Schleicher M, Kimmel AR: A rapid and efficient method to generate multiple gene disruptions in Dictyostelium discoideum using a single selectable marker and the Cre-loxP system. Nucleic Acids Res 2004, 32(19):e143.

61. Detterbeck S, Morandini P, Wetterauer B, Bachmair A, Fischer K, MacWilliams HK: The 'prespore-like cells' of Dictyostelium have ceased to express a prespore gene: Analysis using short-lived beta-galactosidases as reporters. Development 1994, 120:2847-2855.

62. Jermyn KA, Williams JG: An analysis of culmination in Dictyostelium using prestalk and stalk-specific cell autonomous markers. Development 1991, 111:779-787.

63. Meima ME, Weening KE, Schaap P: Vectors for expression of proteins with single or combinatorial fluorescent protein and tandem affinity purification tags in Dictyostelium. Protein Expr Purif 2007, 53(2):283-288.

64. Escalante $R$, Sastre L: Investigating gene expression: In situ hybridization and reporter genes. In Dictyostelium discoideum protocols. vol. 346. Edited by Eichinger L, Rivero F. Totowa, NJ: Humana Press; 2006:230-247.

65. Serafimidis I, Kay RR: New prestalk and prespore inducing signals in Dictyostelium. Dev Biol 2005, 282(2):432-441.

66. Trapnell C, Pachter L, Salzberg SL: TopHat: discovering splice junctions with RNA-Seq. Bioinformatics 2009, 25(9):1105-1111.

67. Anders S, Huber W: Differential expression analysis for sequence count data. Genome Biol 2010, 11(10):106.

doi:10.1186/1471-213X-13-12

Cite this article as: Galardi-Castilla et al: Mef2A, a homologue of animal Mef2 transcription factors, regulates cell differentiation in Dictyostelium discoideum. BMC Developmental Biology 2013 13:12.

\section{Submit your next manuscript to BioMed Central and take full advantage of:}

- Convenient online submission

- Thorough peer review

- No space constraints or color figure charges

- Immediate publication on acceptance

- Inclusion in PubMed, CAS, Scopus and Google Scholar

- Research which is freely available for redistribution

Submit your manuscript at www.biomedcentral.com/submit
C Biomed Central 